\title{
Si queremos evitar la ira divina: Impacto y vicisitudes del proyecto eclesiológico de Isidoro de Sevilla (c. 630-c. 690)*
}

\author{
If We Wish to Avoid Divine Wrath: The Impact and Development \\ of Isidore of Seville's (c. 630-c. 690) Ecclesiological Project
}

ELEONORA DeLL'Elicine**

\begin{abstract}
RESUMEN
Preocupado por asegurar la salvación de la feligresía vigilando la buena marcha de los asuntos públicos y elevando el nivel de formación del clero, el proyecto isidoriano resultó fundamental en la vertebración del reino visigodo. Índice de su potencia son los sucesivos ajustes que otorgan los obispos al diseño original con el fin de adecuarlo a las nuevas circunstancias.

Durante el transcurso del siglo, otros proyectos de sociedad se elaboran modificando aspectos o cuestionando radicalmente los supuestos que nutrían al diseño oficial. En la heterogeneidad de las fuerzas, dos tendencias progresivas atraviesan todo el espectro social: una apelación cada vez más marcada al lenguaje apocalíptico, y una verticalización creciente de las relaciones sociales.
\end{abstract}

PALABRAS CLAVE

Visigodos, eclesiología, Isidoro de Sevilla.

\begin{abstract}
The Isidorian project was instrumental in structuring the Visigothic kingdom as it was concerned to ensure the salvation of the faithful by monitoring behaviour in public matters and raising the clergy's level of education. Its transcendence has to do with the bishop's successive adjustments to the original design to accommodate to the new circumstances. During the course of the century, other social projects were developed by modifying some of its aspects or radically questioning the assumptions that sustained the official design. Of the manifold forces in play, two progressive tendencies span the entire social spectrum: an increasingly emphatic call for apocalyptic language and a growing vertical integration of social relationships.
\end{abstract}

\section{KEY WORDS}

Visigoths, ecclesiology, Isidore of Seville.

En el contexto del IV concilio de Toledo, Isidoro, obispo de Sevilla entre 600 y 636 , sentenciaba lo siguiente:

* Fecha de recepción del artículo: 2011-1-12. Fecha de aceptación del artículo: 2011-3-18.

** Instituto de Historia Antigua y Medieval «JL Romero»/ FFyL, Universidad de Buenos Aires/ Instituto de Ciencias, Universidad de General Sarmiento (Argentina). C.e.: eelicine@ungs.edu.ar 
«(..) si queremos evitar la ira divina y deseamos trocar su severidad en clemencia, guardemos para con Dios la veneración religiosa y el temor, y permanezcamos hasta la muerte en la fidelidad y promesas que hemos hecho a nuestros reyes. ${ }^{1}$

«Si queremos evitar la ira divina».... He aquí una clave importante para entender el pensamiento y acción pastoral del doctor visigodo.

Una lectura ligera de este fragmento nos podría llevar a considerar a Isidoro un partidario inveterado de la monarquía: sin embargo, la confrontación con otros textos suyos ${ }^{2}$ y este condicional de advertencia — «si queremos evitar la ira divina»-, nos induce a suponer que su apoyo a la realeza responde a motivos más profundos que el apego a las púrpuras y boatos.

Sea cual fuere la opinión que a Isidoro le despierte la institución regia en particular, lo cierto es que el enunciado homilético juzga condición necesaria para la salvación de estos hombres su permanencia en la fidelidad con los reyes. Este lazo

1 Concilio de Toledo IV, Canon LXXV, en VIVES, J. (ed.), Concilios visigóticos e hispanorromanos, Barcelona-Madrid, CSIC, 1963. La edición crítica más reciente de Martínez Díez asienta el texto de este modo: «Quod si divinam iracundiam vitare volumus et severitatem eius ad clementiam provocare cupimus, servermus erga principes nostros pollicitam fidem atque sponsionem. " Concilio de Toledo IV, LXXV, 126-130; en MARTÍNEZ DÍEZ, G.-RODRÍGUEZ, F. (eds.), La colección canónica hispana. Tomo V. Concilios hispanos, segunda parte, Madrid, CSIC, 1992 —esta última será la edición citada en las notas del presente trabajo. Para el estudio de la colección canónica hispana, los clásicos de ORLANDIS, J.RAMOS LISSÓN, D., Historia de los concilios de la España Romana y visigoda, Pamplona, Eunsa, 1986; SÁNCHEZ HERRERO, J., «Concilios y sínodos hispanos e historia de la Iglesia española», Hispania, 175 vol. L/2 (1990), pp. 531-552; y STOCKING, R., Bishops, Councils and Consensus in the Visigothic Kingdom, 589-633, Michigan, 2003. Más generales, se recomiendan HARRIS, J., «Episcopalis audientia», en HARRIS, J., Law and Empire in Late Antiquity, Cambridge, Cambridge University Press, 2004; MARTíNEZ DÍEZ, G., «La Iglesia de las normas: el derecho canónico», en AAVV., La reforma gregoriana y su proyección en la cristiandad occidental, ss. XI-XII, Actas de la XXXII semana de Estudios Medievales, Estella, 18 a 22 de julio de 2005, Pamplona, Fondo de publicaciones del Gobierno de Navarra, 2006; BASDEVANT-GAUDEMET, B., “L'éveque d'après la législation de quelques conciles mérovingiennes», en Église et autorités. Études d'histoire du droit canonique médiéval, París, Pulim, 2006; NELSON, J., «Law and its applications», en NOBLE, T.; SMITH, J., The Cambridge History of Christianity. Early Medieval Christianities (600-1100), Cambridge, Cambridge University Press, 2008, entre otros.

2 Resulta ya célebre el desarrollo teórico sobre la realeza que Isidoro realiza en Sent. III, 48, 7. Incluso en este mismo párrafo, Isidoro se permite recordar que los viri sancti que poblaron las filas de la Iglesia también podían ser llamados reyes. Al igual que tanto de la escritura isidoriana, esta anotación casi ligera podía cobijar varias interpretaciones posibles: ¿Se trataría de una insistencia más en la rectitud debida por el rey? ¿Apuntaría a reforzar el carácter compartido de las responsabilidades del gobierno? ¿Buscaría rebajar la dimensión singular de la realeza? Lo cierto es que lejísimo estaba del texto isidoriano zanjar doctrina en este punto: por el contrario, su pretensión era acotar las pretensiones de autoridad de la monarquía. En estos temas, no podemos sino remitir a un artículo antiguo, pero profundamente sugerente si consideramos el momento de su escritura, primer peronismo y franquismo campantes: ROMERO, J.L., "San Isidoro de Sevilla. Su pensamiento históricopolítico y sus relaciones con la historia visigoda», CHE, VIII (1947), p. 5-71, particularmente sobre este punto las hipótesis que esboza en p. 19. Resulta también insoslayable desde el punto de vista historiográfico el artículo ya clásico de BARBERO, A., «El pensamiento político visigodo y las primeras unciones regias en la Europa medieval», Hispania, 115 (1970); especialmente pp. 265 y ss., y el de CAZIER, P., «Les Sentences d'Isidore de Séville et le IVe Concile de Tolède. Réflexions sur les rapports entre l'Eglise et le pouvoir politique en Espagne autour des années 630", en Los visigodos. Historia y civilización. Antigüedad y Cristianismo, 3 (Murcia, 1986), pp. 376-386. 
entre soteriología y monarquía que el hispalense remarca va a ser espinal en la dinámica del reino visigodo ${ }^{3}$. Lo que nos proponemos estudiar en este trabajo es, precisamente, los ajustes y modificaciones que este postulado experimenta en manos de las generaciones posteriores a Isidoro, desde la muerte del doctor hasta aproximadamente 700; y los efectos prácticos que esto conlleva. En este plan, y por meras razones de espacio, nos centraremos fundamentalmente en las intervenciones de Tajón, Fructuoso, Julián y Valerio del Bierzo.

\section{EL PROYECTO ISIDORIANO}

En el plano intelectual, Isidoro es heredero directo de la coyuntura y conceptos que dieron vida al Concilio de Toledo III de 589, a partir del cual se reconoce al rey como conductor de un populus unido por los lazos de la fe $\mathrm{f}^{4}$. Jurídicamente, la misión que recibe el monarca no es sólo velar por los negocios del siglo, sino garantizar la ortodoxia, defender a la iglesia e implementar castigos ${ }^{5}$.

${ }^{3}$ Esta relación entre soteriología y monarquía campa por todas las obras de Isidoro, especialmente en las intervenciones jurídicas —-como hemos visto-, pero también en las obras historiográficas. En el siguiente pasaje panegírico de Recaredo se advierte con nitidez: «Multos etiam ditavit rebus, plurimos sublimavit honoribus, opes suas in miseris, thesauros suos in egenis recondens, sciens ad hoc illi fuisse conlatum regnum ut eo salubriter frueretur, bonis initiis bonum finem adeptus; fidem enim rectae gloriae, quam initio regni percepit, novissime publica confessione paenitentiae cumulavit." Isid. Hisp., Hist. Goth. 56, 1-10, en RODRíGUEZ ALONSO, C. (ed.), Las historias de los godos, vándalos y suevos de Isidoro de Sevilla. Estudio, edición crítica y traducción, León, Centro de Estudios e Investigación «San Isidro», 1975.

4 «Properet ergo reverentia vestra fidem hanc nostram canonicis applicare monumentis, et ab episcopis vel religiosis aut gentis nostrae primoribus sollerter fidem quam in ecclesia catholica Deo crediderunt, audite; quam renotatam apicibus vel eorum subscriptionibus roboratam futuris olim temporibus in testimonium Dei atque hominum reservate, ut eae gentes, quorum in Dei nomine regia potestate praecellimus et quae deterso antiquo errore per untionem sacrosancti chrismatis vel manus impositionem Paraclitum intra Dei ecclesiam perceperunt Spriritum — quem unum et aequalem cum Patre et Filio confitentes eiusque dono in sinu ecclesiae sanctae catholicae collocatae sunt-, si eorum aliqui hanc rectam et sanctam confessionem nostram minime credere volverint, ira Dei cum anathemate aeterno percipiant et de interitu suo fidelibus gaudium, infidelibus sint in exemplum.» Tol. III, Regis Professio fidei 154-169. Una discusión interesante en relación al rol del rey en la coyuntura Leovigildo-Recaredo en DÍAZ MARTÍNEZ, P., «Rey y poder en la monarquía visigoda», Iberia, 1 (1998), pp. 175-95, especialmente pp. 184 y ss., y KOCH, M., «La imperialización del Reino visigodo bajo Leovigildo. ¿Es la imitatio imperii de Leovigildo la manifestación de un momento de cambio en la pretensión de poder y la ideología visigodas?», en Pyrenae, 39, vol. 2 (2008), pp. 101-117.

5 «Sic enim audit qui super id quam quod ei committitur augit dum illi dicitur: «Quicquid superogaveris, ego cum redierom reddam tibi». Ergo quia iam fidei nostrae et confessionis formam plena serie vestra beatitudo recensuit simulque et sacerdotum nostrorumque procerum fides atque confessio sanctitati vestra beatitudo recensuit simulque et sacerdotum nostrorumque procerum fides confessio sanctitati vestrae perpatuit, hoc adhuc necessario pro firmitate catholicae fidei nostra Deo supplex instituere decrevit auctoritas, ut propter roborandam gentis nostrae novellam conversionem omnes Spaniarum et Galliae ecclesiae hanc regulam servent, ut omni sacrificii tempore ante communicationem corporis Christi vel sanguinis iuxta Orientalium partium morem unanimiter clara voce sacratissimum fidei recenseant symbolum, ut primum populi quid credulitate teneant fateantur et sic corda fide purificata ad Christi corpus et sanguinem percipiendum exhibeant.» Tol. III, Canones, 611-625. Tol. III, 611-625. 
Desde el punto de vista de la situación interna del reino y especialmente a partir de la entronización de Sisebuto (612-621), Isidoro se atiene a formalizar teórica y retóricamente el catálogo de virtutes dignas del buen rey ${ }^{6}$, así como a instituir desde el plano jurídico e intelectual los criterios de sucesión regia ${ }^{7}$. Fronteras afuera, la coyuntura pendía con aristas dramáticas de la guerra entre bizantinos y persas: a partir de 613, estos últimos habían arrancado de manos cristianas provincias estratégicas como Armenia, Palestina y Egipto, capturando la Ciudad Santa y sus reliquias en 614. La reacción de los griegos sólo se organizaría a partir de 622 , e Isidoro moriría sin verla recuperada para el bando de Cristo ${ }^{8}$. En un artículo ya clásico, Juan Gil señaló con justeza el peso de esta coyuntura bélica en la proliferación de lecturas apocalípticas: en efecto, fue la certeza de una pronta parusía lo que llevó a Sisebuto a decretar el bautismo forzado de judíos en 632, desatando el cuestionamiento áspero de Isidoro ${ }^{9}$.

Como no podía ser de otro modo, el hispalense reflexiona acerca de su circunstancia histórica a la luz de las Sagradas Escrituras, especialmente a partir del libro de Isaías. Allí, el profeta desarrolla imágenes del castigo que se le impartirá a Israel a raíz de sus pecados ${ }^{10}$; al tiempo que exalta la idea de un puñado de ele-

6 Desde el punto de vista teórico, el desarrollo formal más sólido lo recibe en las Sententiae, especialmente en Sent. III, XLVIII (CAZIER, P. (ed.), Isidorus Hispalensis, Sententiae, Turnholt, Brepols, 1998); y desde el punto de vista retórico nuevamente en las Historiae Gothorum. Además del panegírico de Recaredo con el cual ya hemos trabajado, resulta ilustrativo el modo de adjetivar la personalidad y obra a su turno de Sisebuto, Suinthila (621-31) y Sisenando (631-6), a partir del párrafo 60. Para una aproximación a los hechos históricos del período, véanse DÍAZ MARTÍNEZ, P.; MARTÍNEZ MAZA, C.; SANZ HUESMA, F., Hispania tardoantigua y visigoda, Madrid, Istmo, 2007, especialmente pp. 398 y ss., y el clásico de ORLANDIS, J., Historia de España, época visigoda (409-711), Madrid, Gredos, 1987, pp. 128 y ss.; entre otros.

7 Desde el punto de vista jurídico, el desarrollo principal de los criterios de elección y sucesión regias se asientan en el canon LXXV de Tol. IV, en parte citado en el párrafo preliminar. A este respecto, lo relevante aquí es la participación formal que el concilio asigna al clero en la elección del rey. Un análisis jurídico de las intervenciones conciliares de Isidoro en GARCÍA GALLO, A., "San Isidoro jurista», Isidoriana. Estudios sobre san Isidoro de Sevilla en el XIV aniversario de su nacimiento, León, Centro de Estudios San Isidoro, 1969.

8 Varios relatos fácticos de esta situación bélica clave para el siglo VII. Muy operativo DUCELLIER, A.; KAPLAN, M.; MARTIN, B., De los bárbaros a los otomanos. El cercano oriente medieval, Madrid, Akal, 1988, pp. 54.

9 GIL, J., «Judíos y cristianos en la Hispania del siglo VII», Hispania Sacra 30 (1977), especialmente pp. 3 y ss. Generales para el tratamiento de la apocalíptica SCHIFFMAN, L., «Messianism and apocalypticism in rabbinic texts", en KATZ, S. (ed.), The Cambridge History of Judaism, Volume IV: The Late Roman-Rabbinic period, Cambridge, Cambridge University Press, 2008; DE MARTIN DE VIVIÉS, P., Apocalypses et cosmologie du salut, Cerf, París, 2002; VANDERKAM, J.; ADLER, W., The Jewish apocalyptic heritage in early Christianity, Assen-Minneapolis, Van Gorcum-Fortress Press, 1996. Su conexión con el reino visigodo MARTIN, C., La geographie du pouvoir dans l'Espagne visgothique, París, Septentrion, 2003; GARCÍA MORENO, L., Los judíos de la España antigua. Del primer encuentro al primer repudio, Madrid, Rialp, 1993; idem, «Expectativas milenaristas y escatológicas en la España tardoantigua», Arqueología, Paleontología y Etnografía, 4 (1997), pp. 247-58. Sobre la relación puntual de Isidoro en relación a los judíos hay mucha bibliografía, especialmente DíEZ MERINO, L. «San Isidoro de Sevilla y la polémica judeo-cristiana», en del VALLE RODRÍGUEZ, C. (ed.), La controversia judeo-cristiana en España (desde los orígenes hasta el siglo XIII), Madrid, CSIC, 1998; DREWS, W., The unknown neighbour. The Jew in the thought of Isidore of Seville, Brill, Leiden-Boston, 2006.

10 «Ecce Dominus dissipabit terram et nudabit eam et adfliget faciem eius et disperget habitatores eius (2) et erit sicut populus sic sacerdos et sicut servus sic dominus eius sicut ancilla sic domina eius sicut 
gidos que va a ser salvado ${ }^{11}$. A diferencia de Jeremías, que plantea que el pueblo en su conjunto sería rescatado por la compasión de Jahvé12, el primer Isaías trabaja especialmente la idea de elección de un resto que, por permanecer firmes en la justicia, se vería a salvo de la ira divina.

Isidoro interpreta este texto con todas las mediaciones de la tradición patrística largamente desarrollada a esta altura; y particularmente en este punto lo hace bajo la influencia de Agustín ${ }^{13}$. Con el de Hipona, Isidoro identifica de modo preciso a ese resto al que Isaías aludía con la iglesia, nueva nación que, a causa de su fe en el Enviado, había desplazado a Israel en la alianza con Dios. Fuera de la iglesia no existía posibilidad alguna de salvación ${ }^{14}$. A partir de la herencia intelectual e histórica del III concilio toledano, finalmente, Isidoro deposita la conducción de la feligresía asentada en las Hispanias en el rex gothorum ${ }^{15}$. De esta manera, para Isidoro los asuntos de la respublica son directa y llanamente los asuntos de la ecclesia.

Como hemos visto, esto no implica un apoyo incondicional a la monarquía y menos aún a la persona del monarca de turno. En efecto, en la Chronica la reale-

emens sic ille qui vendit sicut fenerator sic is qui mutuum accipit sicut qui repetit sic qui debet (3) dissipatione dissipabitur terra et direptione praedabitur Dominus enim locutus est verbum hoc (4) luxit et defluxit terra et infirmata est defluxit orbis infirmata est altitudo populi terrae (5) et terra interfecta est ab habitatoribus suis quia transgressi sunt leges mutaverunt ius dissipaverunt foedus sempiternum (6) propter hoc maledictio vorabit terram et peccabunt habitatores eius ideoque insanient cultores eius et relinquentur homines pauci» Is. 24, 1-6, WEBER, R. (ed.), Biblia Sacra Vulgata, Hendrikson, 2006.

11 «(20) et erit in die illa non adiciet residuum Israhel et hii qui fugerint de domo lacob inniti super eo qui percutit eos sed innitetur super Dominum Sanctum Israhel in veritate (21) reliquiae convertentur reliquiae inquam lacob ad Deum fortem (22) si enim fuerit populus tuus Israhel quasi harena maris reliquiae convertentur ex eo consummatio adbreviata inundabit iustitiam (23) consummationem enim et adbreviationem Dominus Deus exercituum faciet in medio omnis terrae» Is. 10, 20-3.

12 «Vae pastoribus qui disperdunt et dilacerant gregem pascuae meae dicit Dominus (2) ideo haec dicit Dominus Deus Israhel ad pastores qui pascunt populum meum vos dispersistis gregem meum eiecistis eos et non visitastis eos ecce ego visitabo super vos malitiam studiorum vestrorum ait Dominus (3) et ego congregabo reliquias gregis mei de omnibus terris ad quas eiecero eos illuc et convertam eos ad rura sua et crescent et multiplicabuntur (4) et suscitabo super eos pastores et pascent eos non formidabunt ultra et non pavebunt et nullus quaeretur ex numero dicit Dominus» Jer. 23, 1-4.

${ }_{13}$ "Quod si dementissimum est dimecere, fateantur vero baptismo Christi baptizari posse hominem et tamen cor Rius in malitia vel sacrilegio perserverans peccatorum abolitionem non sinere fieri, adque ita intellegant in communionibus ab ecclesia separatas posse homines baptizari, ubi Christi baptismus eadem sacramenti celebratione datur et sumitur, qui tamen tunc prosit ad remissionem peccatorum, cum quisque reconciliatus unitati sacrilegio dissentionis exvitur, quo eius peccata tenebantur et dimitti non sinebantur.» Ag. Hip., De bapt., XII, 18; en SANTAMARTA DEL RÍO, S; LANGA, P. (eds.), «De baptismi libri VII» Obras completas de san Agustín, XXXII, Madrid, BAC, 1988.

14 «12. 4: Scripturas heretici sano sensu non sapiunt, sed eas ad errorem pravae intellegentiae ducunt; neque semetipsos earum sensibus subdunt, sed eas perverse ad errorem proprium pertrahunt. 12.5: Doctores errorum pravis persuasionibus ita per argumenta fraudulentiae inligant auditores, ut eos quasi in laberinto inplicent, a quo exire vix valent». Isid. Hisp., Sent. III, XII, 4-5.

15 «Dedit Deus principibus praesulatum pro regimine populorum, et illis eos praesse voluit cum quibus una est eis nascendi moriendique conditio. Prodesse ergo debet populis principatus, non nocere, nec dominando premere, sed condescendendo consulere, ut vere sit utile hoc potestatis insigne, et donum Dei pro tuitione utantur membrorum Christi. Membra quippe Christi fideles sunt populi, quos, dum ea potestate quam accipiunt optime regunt, bonam utique vicissitudinem Deo largitori restituunt.» Isid. Hisp., Sent. III, XLIX,.3. 
za como tal aparece recién a partir de la segunda edad en la curva descendente de los tiempos ${ }^{16}$; en Etymologiae IX la condición de rey se enlaza enfáticamente al ejercicio de la piedad y la justicia ${ }^{17}$; en Toledo IV vuelve sobre las obligaciones regias ${ }^{18}$ y finalmente en Sententiae resume y profundiza su planteamiento ${ }^{19}$. Con algunos matices, la postura de Isidoro acerca de la realeza no varía: esta resulta a todas luces un mal necesario ${ }^{20}$. Aún bajo estos reparos, el hispalense remite la presencia de malos reyes a una desviación del pueblo, y propone en consecuencia corregir el extravío antes que desplazar al rey ${ }^{21}$. Como podemos ver, la eclesiología isidoriana brega por el respeto al orden y a las jerarquías asentadas a través de criterios probados por la tradición — cúmulo de enunciados y prácticas que el doctor se está encargando de instituir.

En esta tarea, resulta cardinal la intervención del clero. Isidoro está primordialmente interesado en elevar la formación y la disciplina del sacerdocio, trabajando para tal fin en dos registros complementarios. A nivel pragmático, en el propio clero de la Bética con vistas a instituirlo como modelo para los demás ${ }^{22}$ —en este sentido,

16 «Secunda aetas saeculi (...) Ragau annorum CXXXII genuit Seruch. Sub quo Scitarum regnum exortum est, ubi primus regnavit Tanus.» Isid. Hisp., Chronica 25-6, en MARTIN, J. (ed.), Isidori Hispalensis Chronica, CC SL CXII, Brepols, Turnholt, 2003.

17 «Reges a regendo vocati. Sicut enim sacerdos a sacrificando, ita et rex a regendo. Non autem regit, qui non corrigit. Recte igitur faciendo regis nomen tenetur, peccando ammittitur. Unde et apud veteres tale erat proverbium: «Rex eris, si recte facias: si non facias, non eris». Regiae virtutes praecipuae duae: iustitia et pietas.(...)» Isid. Hisp., Etym. IX, 3, 4-5; en OROZ RETA, J., San Isidoro de Sevilla. Etimologías, Madrid, BAC no 433, 1982.

18 «Te quoque praesentem regem futurosque aetatum sequentium principes humilitate qua debemus deposcimus ut moderati et mites erga subiectos exsistentes cum iustitia et pietate populos a Deo vobis creditos regatis, bonamque vicissitudinem, qui vos constituit, largitori Christo respondeatis regnantes in humilitate cordis cum studio bonae actionis, nec quisquam vestrum solus in causis capitum aut rerum sententiam ferat, sed consensu publico cum rectoribus ex iudicio manifesto delinquentium culpa patescat, servata vobis inoffensis mansuetudine ut non severitate magis in illis quam indulgentia polleatis, ut dum omnia haec auctore Deo pio a vobis moderamine conservantur, et reges in populis et populi in regibus et Deus in utrisque laetetur.» Tol. IV, Canones, 188-199.

19 «Dum mundi reges sublimiores se ceteris sententiant, mortales tamen se esse agnoscant, nec regni gloriam, qua in saeculo sublimantur, aspiciant, sed opus quod secum ad inferos deportent intendant. Si ergo carebunt huius temporis gloriam, illa agant quae post finem sine fine possideant.» Isid. Hisp., Sent. III, LXVIII, 9. El desarrollo acerca de la monarquía prosigue hasta el capítulo LI inclusive. Para la secuencia de obras de Isidoro que hemos citado, seguimos la cronología empleada por Fontaine en Isidoro de Sevilla. Génesis y originalidad de la cultura hispánica en tiempos de los visigodos, Buenos Aires, Encuentro, 2002, pp. 310-312.

20 «Propter peccatum primi hominis humano generi poena divinitus inlata est servitutis, ita ut quibus aspicit non congruere libertatem, his misericordius inroget servitutem. Et licet per peccatum humanae originis, tamen aequus Deus ideo discrevit hominibus vitam, alios servos constituens, alios dominos, ut licencia male agendi servorum potestate dominantium restringatur. Nam si omnes sine metu fuissent, quis esset qui a malis quempiam cohiberet? Inde et in gentibus principes repesque electi sunt, ut terrore suo populos a malo coercerent, atque ad recte vivendum legibus subderent.» Isid. Hisp., Sent. III, XLVII, 1.

21 «Reges quando boni sunt, muneris esse Dei; quando vero mali, sceleris esse populi. Secundum meritum enim plebium disponitur vita rectorum, testante lob: Qui regnare facit hypocritam propter peccata populi. Irascente enim Deo, talem rectorem populi suscipiunt, qualem pro peccato merentur. Nonnumquam pro malitia plebis etiam reges mutantur, et qui ante videbantur esse boni, accepto regno fiunt iniquit». Isid. Hisp., Sent. III, LXVIII, 11.

22 Efectivamente, aunque el contenido de los cánones y la dirección a la que apuntan puedan acercarse, no se debe perder de vista que Sevilla II tiene un carácter provincial y Toledo IV un alcance na- 
el concilio IV de Toledo representa un punto de inflexión en tanto que ya no busca disciplinar a través de modelos sino a partir de cánones sinodiales con valor legislativo para todas las diócesis del reino. A nivel teórico, a través de obras formativas, exegéticas e historiográficas para otorgar herramientas y legitimidad a su proyecto ${ }^{23}$.

El último rasgo importante de la eclesiología isidoriana que resulta necesario revelar es su opinión acerca de los milagros. Sabemos que entre los visigodos es el rey Sisebuto quien inicia la tradición de recoger por escrito los milagros de un obispo fallecido poco tiempo atrás ${ }^{24}$. Por su parte también Gregorio Magno, preocupado por quienes sostenían que la falta de milagros en el presente indicaba una sustracción de la Gracia, se muestra partidario de dar a conocer los signos que patentizan la vigencia de la promesa divina para con la Iglesia ${ }^{25}$. No es el caso de Isi-

cional. Un ejemplo del modo de disciplinar al clero bético: «De his quae prohibentur presbyteris in ecclesiasticis sacramentis: Septimo examine relatum est nobis venerantissimus quondam Agapium Cordobensis sedis episcopum frequenter presbyteres destinasse, qui absente pontifice altaria erigerent, basilicas consecrarent: quod quidem non est mirum id praecipisse virum ecclesiasticis disciplinis ignarum et statim a saeculari militia in sacerdotale ministerium delegatum. Ergo ne ultra talis a nobis licentia usurpetur, conmuni sententia statuendum oportuit, scientes quia sicut presbytero inlicita consecratio est altarium, ita est constitutio. In divinis enjim litteris praecipiente Domino solus Moyses in tabernaculo Dei erexit altare, solus ipse unxit, utique quia summus sacerdos Dei erat, sicut scribtum est de eo: Moyses et Aaron in sacerdotibus eius. [Ideoque] id quod tantum facere principibus sacerdotum iussum est, quarum typum Moyses et tenuerunt, presbyteres, qui filiorum Aaron gestant figuram, arripere non praesumant. (...)». Sev. II, VII [citado de acuerdo a edición VIVES].

${ }^{23}$ El interés por elevar el nivel de formación y de disciplina del clero despunta desde las obras más tempranas de Isidoro. Cuando presenta en el De Ecclesiasticis officiis, por ejemplo, los rasgos fundamentales del programa clerical, escribe lo siguiente: "Tales enim esse debent quique divinis cultibus sese mancipandos student, scilicet ut dum scientiae operam dant doctrinam gratiam populis administrent." Isid. Hisp., DEO II, 2, 25-8; en LAWSON, C. (ed.) Sancti Isidori episcopi Hispalensis «De Ecclesiasticis Officiis», Turnholt, CCSL 113, 1989. Para este tema, FONTAINE, J., «Grammaire sacrée et grammaire profane: Isidore de Séville devant l'exégese biblique», Antigüedad y cristianismo III (1986), pp. 311-329, y más general, idem, Isidore de Séville et la culture classique dans l'Espagne wisigothique, París, Études Augustiniennes, 1959 (2 vols); DÍAZ Y DÍAZ, M., Enciclopedismo e sapere cristiano tra tardo-antico e alto medioevo, Milán, 1999, especialmente pp. 109 y ss.; GONZÁLEZ FERNÁNDEZ, J. (coord.), San Isidoro, doctor Hispaniae, Fundación El Monte-Universidad de Sevilla, Sevilla 2002.

${ }^{24}$ Se trata de la Vita Desiderii, redactada hacia 613. Observemos al punto un ejemplo de cómo el rey revela uno a uno los milagros ocurridos poco tiempo atrás: «De sus milagros [de Desiderio] he decidido seleccionar tres, aun cuando mi sobrio estilo se resienta por la falta de técnica. En cierta ocasión vino a visitarle un gran gentío. Ordenó él que, como es costumbre, les sirvieran de comer y de beber. Un sirviente le comunicó que la presencia del vino, lo más solicitado, era lo que más les había faltado. El recipiente en el que se había consumido la bebida mandó que se lo mostraran. Hecha la señal de la cruz, por la gracia del Salvador, se volvió a llenar con la generosidad de un vino excelente. De este modo la muchedumbre que acudió se restableció con la bendición al tiempo que con la mística bebida.» Sis., Vita Des., 12, en DÍAZ y DÍAZ, M. (ed.), «Tres biografías latino medievales de san Desiderio de Viena. Traducción y notas", Fortunatae, 5 (1993). El milagro, como vemos, está rodeado de todas las señales del mando: la presencia del sirviente, la orden, el cumplimiento de lo solicitado por parte de la divinidad. Advirtamos de paso cómo semantiza directamente apoyándose en el relato de las bodas de Canaán (Ver Jn. 2, 1-12). Para esta vita, FONTAINE, J., «King Sisebut's Vita Desiderii and the Political function of Visigothic Hagiography», en JAMES, E. (comp.), Visigothic Spain. New approaches, Oxford, Oxford University Press, 1980; MARTIN, J.C., "Caracterización de personajes y tópicos del género hagiográfico en la Vita Desiderii de Sisebuto", Helmantica XLVIII no 147 (1997), pp. 111-33.

25 «Petrus: Vellem quaerenti mihi de eis aliqua narrarares, neque hac pro re interrumpere expositionis Studium grave videatur, quia non dispar aedificatio oritur ex memoria virtutum. In expositione quippe qualiter invenienda atque tenenda sit virtus agnoscitur, in narratione vero signorum congnoscimus inventa ac retenta qualiter declaratur. Et sunt nonnulli quos ad amorem patriae caelestis plus exempla quam praedi- 
doro, quien, perfectamente al corriente de estas posiciones, se atiene una vez más a la postura conservadora. Para el obispo de Hispalis, en época de los apóstoles los signos y milagros constituían una forma eficaz de difundir la fe entre los que todavía no creían; pero en los tiempos presentes, cuando la Iglesia es dominante, esos signos se vuelven a su criterio innecesarios e inclusive peligrosos ${ }^{26}$. En efecto, considera que los portentos son señales del Anticristo, y por lo tanto sólo medios de confusión para los probos ${ }^{27}$.

Sintetizando lo examinado hasta aquí, podemos afirmar que, coherente con una ideología atenta pero no torturada con final de los tiempos ${ }^{28}$, la eclesiología isidoriana se puede resumir en tres puntos nodales: respeto por el orden y jerarquías instituidas, inclusión formal del clero en las tomas de decisión y por último una desestimación del expediente milagroso.

\section{TAJÓN Y FRUCTUOSO}

En torno a 653, Tajón, obispo de Zaragoza entre 651 y circa 680, escribió una de sus obras más conocidas, las Sententiarum libri quinque, emulando en título y género al conocido texto de Isidoro.

Habían pasado unos 17 años de la muerte del maestro, y la coyuntura había experimentado un cambio de envergadura. En el interior del reino, las administraciones de Chindasvinto (642-653) y su hijo Recesvinto (653-72) resultaron eficaces a la hora de sostener una política centralista en provecho de la monarquía: la sucesión filial, la promulgación inminente de un código monopólico de leyes y la serie de medidas en contra de los judíos son índices claros de esta reorganiza-

camenta succedunt. Fit vero plerumque in audientis animo duplex adiutorium in exemplis patrum, quia et ad amorem venturae vitae ex praecedentium conparatione accenditur, et iam si se esse aliquid aestimat, dum de aliis meliora cognoverit, humiliatur. Gregorius: Ea quae mihi sunt virorum venerabilium narratione conperta incunctanter narro sacrae auctoritatis exemplo, cum mihi luce clarius constet quia Marcus et Lucas evangelium quod scripserunt, non visu sed auditu didicerunt. Sed ut dubitationis occasionem legentibus subtraham, per singula quae describo, quibus mihi haec auctoribus sint conperta manifesto. Hoc vero scire te cupio quia in quibusdam sensum solummodo, in quibusdam vero et verba cum sensu teneo, quia si de personis omnibus ipsa specialiter et verba tenere voluissem, haec rusticano usu prolata stilus scribentis non apte susciperet. Seniorum valde venerabilium didici realtione cum narro.» Greg. Magn., Dial., LI, 9-10, en De VOGÜE, A.; ANTIN, P. (eds), Grégoire le Grand, Dialogues, T. II, Paris, ed. Du Cerf, 1979.

${ }_{26}$ «De sanctorum miraculis: Etsi apostolis virtus data est signorum procter fidem gentium nutriendam, ecclesiae tamen data est virtus operum pro eandem fidem ornandam, et tamen in ipsis apostolis plus erat mirabilis virtus operum quam virtus signorum. Ita nunc et in ecclesia plus est bene vivere quam signa facere.» Isid. Hisp., Sent. I, 24,1.

27 «Ob hanc utilitatem cessabunt sub Antichristo ab ecclesia miracula et virtutes, ut per hoc sanctorum clareat patientia et reproborum qui scandalizabuntur levitas ostendatur, et persequentium audacia ferocior efficiatur.» Isid. Hisp., Sent. III, 24, 4b.

${ }_{28}$ El editor de las Sententiae, Cazier, señala en relación a este punto que «/sidore semble insister sur la victoire finale des élus et de l'Église, plutôt que sur l'aspect terrible du jugement.» CAZIER, P., op. cit., pp. XXIV.

29 «Escoger los reinados de Chindasvinto y Recesvinto para detenernos a explicar la organización administrativa del reino visigodo responde a un motivo de clara oportunidad. Ellos dieron forma, de una ma- 
ción ${ }^{29}$. Fronteras afuera, la irrupción del Islam modificó por completo el elenco de las fuerzas en pugna. Dos años después de la muerte de Isidoro, en efecto, la Ciudad Santa es arrancada de las ortodoxas manos de Heraclio para caer bajo el imperio de los infieles; en 641 las huestes islámicas se hacen con Egipto; en 644 con el Imperio Sasánida y en 651 han llegado a Jurasán ${ }^{30}$. Estos sucesos dramáticos son interpretados por judíos y cristianos una vez más en clave escatológica: aunque no resulta probable que las proposiciones de Pseudo Metodio hayan sido conocidas en Occidente antes de $700^{31}$, profecías milenaristas o escatológicas en general campaban sin más por los círculos expectantes de judíos y de cristianos del reino ${ }^{32}$.

Al igual que su referente Isidoro, Tajón es un partidario del orden ${ }^{33}$, del respeto por las instituciones ${ }^{34}$, de elevar el nivel de formación intelectual y disciplinar del clero $^{35} \ldots$ y de las citas de autoridad de Gregorio Magno ${ }^{36}$. De modo semejante al

nera más o menos ordenada, a toda una serie de iniciativas y tendencias que procedían de la propia tradición germánica, sobre todo en la faceta militar y guerrera, y especialmente de las estrucutras precedentes bajoimperiales y de la influencia bizantina. Es este sentido, la coincidencia de la reorganización administrativa y de la promulgación del Liber ludiciorum responde a un mismo criterio de unificación de las formas y estructuras del reino, a un afán por poner orden en una situación que desde los tiempos de Leovigildo apenas había hecho otra cosa que improvisar.» DÍAZ MARTíNEZ, P. y otros, op. cit., pp. 440. Un panorama fáctico de esta coyuntura en BARBERO, A.; LORING, I., «The Catholic Visigothic kingdom», en FOURACRE, P. (ed.), The new Cambridge medieval history, vol. I (500-700), Cambridge, Cambridge University Press, 2005, especialmente pp. 356 y ss.; y nuevamente en ORLANDIS, J., op. cit., pp. 151-66. En apoyo a la teoría de la centralización progresiva, MARTIN, C., op. cit., especialmente pp. 143 y ss. Para la política antijudía de Recesvinto, DUMÉZIL, B., Les racines chrétinennes de l'Europe. Conversion et liberté dans les royaumes barbares (Ve-VIIle siècles), Fayard, París, 200, pp. 295 y ss.

30 Nuevamente un panorama fáctico rápido en HILLENBRAND, C., «Muhammad and the rise of Islam», en FOURACRE, P., op. cit., pp. 317-45; DUCELLIER A., y otros, op. cit., pp. 50 y ss.; COLLINS, R., «The Arab conquest», en Early Medieval Spain. Unity in diversity, 400-1000, Hampshire, Macmillan, 1995 pp. 146 y ss.; KENNEDY, H. «The mediterranean frontier: Christianity face to face with Islam (6001050)», en NOBLE, T; SMITH, J., op. cit.., entre otros.

31 HILLGARTH, J., «Escathological and political Concepts», en FONTAINE, J.; HILLGARTH, J., The seventh century, change and continuity, Londres, University of London, pp. 228.

32 Para la relación de Tajón con los judíos, especialmente DEL VALLE, C., «Tajón de Zaragoza (ca. 600-680)«en DEL VALLE, C., op. cit.

33 «Caput XXXIII: De Rectoribus, qualiter vitae converationem habeant: Necessarium valde rectoribus est ut cura regiminis tanta moderaminis arte temperetur, quatenus subditorum mens, cum quaedam recta sentire potuerit, sic in vocis libertatem prodeat, ut tamen libertas in superbiam non erumpat; ne dum fortasse immoderatius linguae eis libertas conceditur, vitae ab his humilitas amittatur». Taio Caes., Sent. II, XXXIII, col. 826, en TAIO CAESARAUGUSTANUS, Sententiarum libri quinque, PL LXXX, col. 727-990.

34 «Princeps terrenam rempublicam gerens aliter punuit civem interius delinquentem, atque aliter hostem exterius rebellantem (Moral. XXVI, c. 27, n. 50). In illo jura sua consulit, eumque sub verbis dignae invectionis addicit. Contra hostem vero movet, instrumenta perditionis exercet, dignaque ejus malitiae tormenta retribuit: de malo vero ejius quid lex habeat non requirit; neque enim lege necese est perimi, qui lege nunquam potuit teneri. » Taio Caes., Sent. V, X, col. 965.

35 «Praeconis quippe officium sumit quisquis ad sacerdotium accedit, ut ante adventum iudicis, qui terribiliter sequitur, ipse scilicet clamando gradiatur. Sacerdos ergo si praedicationis est nescius, quam clamoris vocem daturus est praeco mutus? (...)» Taio Caes., Sent. II, XXXII, col. 821. Para el alineamiento de Tajón en relación a Isidoro, CONDE GUERRI, E. «Tajón de Zaragoza y su tradición doctrinal sobre los pastores animarum, Aragón en la Edad Media 14-15, 1 (1999), pp. 329-39.

${ }^{36}$ Para un análisis técnico del uso de citas de Gregorio en otro de los textos de Tajón, PALACIO MARTÍN, A., «Tajón de Zaragoza y la explicatio In cantica canticorum, Anuario de Estudios Filológicos, 3 (1980), pp. 115-127. 
hispalense, también Tajón condena las sediciones facciosas y las inscribe entre los enemigos del Pueblo elegido y, por lo tanto, de Jahvés7. Pero no redacta cinco libros de Sententiae para reproducir las soluciones que ya había pensado Isidoro para la coyuntura anterior: la intervención de Tajón propone modificaciones y ajustes a un esquema heredado en sus líneas fundamentales.

El primer índice del ajuste es el tono general de la obra: su escatología, efectivamente, es más amenazante y punitiva que la de su referente Isidoro ${ }^{38}$; su descripción del anticristo más detallada y precisa ${ }^{39}$. Tan relevante como esto y en el mismo plan, debemos resaltar la incoporación del expediente milagroso a la dogmática oficial. Ciertamente, en la generación que sigue a Isidoro ya Braulio de Zaragoza (631-651) — discípulo directo del de Hispalis- había revelado producción de milagros dentro del perímetro del reino ${ }^{40}$. Formado a su turno por Braulio,

37 En el prólogo de las Sententiarum libri V que Tajón dedica a su colega Quirico de Barcelona, describe en términos amargos la situación bajo la cual se vio obligado a tomar la pluma. En efecto, el noble Froia se había rebelado contra la autoridad legítima de Recesvinto y, para amedrentar, había movilizado a los vascones para que sitiaran la ciudad de Zaragoza. En su recuento, Tajón se apoya explícitamente para que el lector lo atienda en el salmo 78: «Heu, pro dolor! (...) Innoxius quippe multorum Christianorum sanguis effunditur: alii jugulis, nonnulli missilibus, plerique diversis jaculis sauciantur, innumerabilis multitudo captivorum abducitur, inmensa spolia subtrahuntur. Templis Dei infaustum bellum infertur, sacra alteris destruuntur, atque inumata canibus avibusque multorum exponuntur cadavera occisorum: ita ut septuagesimi octavi psalmi non immerito illi ea calamitati congrua videatur inscriptio» Taio Caes., Sent., Praef., 2, col. 727-28. El salmo 78, ciertamente, nos avisa que son malditos los bárbaros que han propinado tamaña desgracia en la heredad del Señor $-\mathrm{y}$ con ellos todos los que los han incitado. Hay bárbaros que desconocen el nombre de Dios; pero entre los que lo conocen, elegidos y réprobos no tendrán el mismo destino. Las Sententiarum promueven una contrición del corazón en el marco estricto del respeto a las jerarquías y a la ortodoxia.

38 Las Sententiae de Isidoro terminan —como sabemos- en una reflexión acerca de la muerte; en cambio, las de Tajón lo hacen con un cuadro sobre el suplicio de los réprobos. De todas maneras, demos un ejemplo del tono de Tajón: "De ira vel indignatione Dei: Ira omnipotentis Dei in hoc quotidie vim suae districtionis peragit, quod viventes indigne dignis suppliciis demergit (Moral. XII, c. 10, n. 14). Quae ira nunc equidem transit, sed in fine pertransit, quia modo agitur, sed in mundi termino consummatur. Iste furor quantum ad electorum animas, in Redemptoris nostri adventum pertransiit, quia eas ab inferni claustris ad paradisi gaudia mediator Dei et hominum, dum ipse illuc pie descenderet, reduxit. (...)» Taio Caes. Sent. V, XXII, col. 975-6.

39 Comparar, por ejemplo, Isid. Hisp. Sent. I, XXV con Taio Caes., Sent. V, XXVII.

40 «Volo autem ut, quia sanctissimus vir Cinonatus presbyter atque Gerontius adhuc in corpore degent, omnia quae in eo conscripsi ante ipsi recognoscant, et eorum discussione ventilata, si nec nominum nec rerum me fefellit sentencia, habeantur confirmata. Sane illa quae anno praeterito a vobis ibidem divinitus operata didici, in finem libelli istius ut a vobis accepi adieci.» Br. Caes., Vit. Aem. I, en OROZ, J. (ed.), Sancti Braulionis Caesaraugustani episcopi, Vita santi Aemiliani, Perficit IX, № 119-20 (1978). Observemos que los testigos principales son miembros ellos también de la iglesia. Recordemos brevemente que, de acuerdo a los expertos, la Vida de San Millán fue redactada alrededor de 639-640. Por esos años, los ejércitos islámicos ya habían desbaratado buena parte del orden político que —reinterpretando siempre el esquema de Daniel- se suponía el último del mundo: en 635, efectivamente, caía Damasco, en 636 Ctsifón y, como si de naipes se tratara, en 638 una vez más la Ciudad Santa. En este contexto tan propenso a la interpretación apocalíptica, bien podría ser que Braulio atajara la cuestión retomando la señal de los milagros producidos en Occidente, en una línea de pensamiento cercana a Sisebuto y a la ya larga hagiografía merovingia. La proliferación de milagros, en efecto, parecería indicar una vez más que todavía no era hora y que Occidente también contaba. Análisis de la Vita Aemiliani en VALCÁRCEL, V., «La Vita Emiliani de Braulio de Zaragoza: el autor, la cronología y los motivos para su redacción», en Helmantica, XLVIII, № 147 (1997), pp. 375408; DÍAZ y DÍAZ, M., «Passionaires, légendiers et compilations hagiographiques dans le haut Moyen Âge espagnol», en Vie chrétienne et culture dans l'Espagne du VIle au Xe siècles, Hampshire, Variorum, 1992, especialmente pp. 53 y ss.; LYNCH, 
Tajón da crédito a la generación de prodigios pero los encuadra dentro de la iglesia/ institución: para el obipo novel, a diferencia de Isidoro, los milagros se producen en el presente e incluso de modo cotidiano, pero no por cualquier personaje ignoto sino por sacerdotes y exorcistas debidamente ordenados de acuerdo al ritual legítimo ${ }^{41}$. De este modo, como podemos advertir, Tajón otorga ciudadanía al milagro, expediente con el cual la generación de la que participa interpreta el curso general de los acontecimientos y se asegura la continuidad de la gracia divina. De acuerdo al obispo zaragozano, los milagros efectivamente existen pero son producidos, sancionados e interpretados por la jerarquía eclesiástica. A dos generaciones distantes de Isidoro, en suma, Tajón toma nota de la nueva coyuntura incorporando la lengua de la situación; mas lo hace manteniendo la preceptiva fundamental de Isidoro, ese lazo entre soteriología y ecclesia que redunda en un respeto a las instituciones y jerarquías reconocidas.

La respuesta de estos obispos encumbrados no fue la única que se le dio a la situación. Más joven que Braulio y contemporáneo de Tajón, Fructuoso de Braga promovió una activa campaña de fundación de monasterios a partir del lejano Bierzo, continuando por la Bética, y a la que solo puso término su muerte en $665^{42}$. Como muestra la regla que compuso, numerosos puntos de contacto enlazan el pensamiento de este noble visigodo con el del obispo sevillano ${ }^{43}$ : al igual que Isidoro, Fructuoso califica a los monjes como famuli Christi ${ }^{44}$; le concede primerísima importan-

C.; GALINDO, P., San Braulio, Obispo de Zaragoza. Su vida y sus obras, Madrid, CSIC, 1950; entre otros.

41 «Sancta Ecclesia quotidie miracula spiritaliter facit, quod prisco tempore per sanctos apostolos corporaliter faciebat, sicut scriptum est: Signa autem eos qui credituri sunt, haec sequentur: in nomine meo daemonia ejicient, linguis loquentur novis, serpentes tollent, et si mortiferum quid biberint, non eis nocebit: super aegros manus imponent, et bene habebunt (Marc. XVI, 17). Sacerdotes Ecclesiae cum per exorcismi gratiam manum credentibus imponunt, et habitare malignos spiritus in eorum mente contradicunt, quid aliud faciunt nisi daemonia ejiciunt?» Taio Caes., Sent. III, 17, col. 870.

42 Para un contexto de la vida de Fructuoso DíEZ GONZÁLEZ, F., y otros, San Fructuoso de Braga y su tiempo, León, 1966. Un texto reciente acerca de las fundaciones fructuosianas, cf. LÓPEZ QUIROGA, J.; MARTÍNEZ TEJERA, A., «Un monasterium fructuosiano por descubrir: el de Compludo, en el Bierzo (pcia. de León)» Argutorio, 18 (2007), pp. 43-7.

${ }^{43}$ Díaz y Díaz ya señala la conexión entre Fructuoso e Isidoro: «Nos hallamos, pues, ante un hecho interesante. En varios códices la regula Isidori iba unida, y pospuesta, a la regula monastica de Fructuoso de Braga. Si ahora tenemos en cuenta que el gran impulsor del monacato galaico conoció y utilizó con certeza la regula isidoriana no parece caber más que una solución: en un ambiente fructuosiano la regla del Hispalense, rodeada del prestigio que le confirió el aprecio que por ella sentía san Fructuoso, fue incorporada al codex regularum, ordenado total o parcialmente por Fructuoso que había añadido al final su propia Regla, a la que ahora vino a sumarse la isidoriana.» DÍAZ y DÍAZ, "Aspectos de la tradición de la Regula Isidori», en op. cit., pp. 31. El registro documental también lo hace: ya la Vita Fructuosi compara a su héroe con el egregius doctor de Hispalis (cf. Vit. S. Fruct. I, 21-4, en NOCK, F. (ed.), The vita sancti Fructuosi. Text with a translation, introduction and commentary, Washington, The Catholic University of America Press, 1946). Un análisis de esta última obra en MAYA SÁNCHEZ, A., «La versión primitiva de la Vita Fructuosi», Habis, 9 (1978), pp. 169-96.

${ }_{44}$ Respecto a este punto, resulta relevante notar que, mientras Isidoro utiliza con mayor frecuencia el epíteto miles Xpi, Fructuoso hace uso mayor del Famulus Xpi, posiblemente porque, dado su origen aristocrático, se sienta más familiarizado con el vocabulario de la subordinación propio del linaje. De todas maneras, esta última fórmula es una de las más explotadas en el registro epigráfico. Para avalar con citas, empecemos por Isidoro: «De habitu monachorum: (...) Ternis autem tunicis et binis pallliis singulisque cucullis contenti erunt servi Xpi, quibus superadicietur melotes pellicia, mapula, manicae quoque, pedu- 
cia a la adhesión a un pacto y a una regla ${ }^{45}$; alterna la formación intelectual de los monjes con el trabajo manual ${ }^{46}$, prohíbe expresamente la propiedad privada en el interior del monasterio ${ }^{47}$ y no resta colaboración a los asuntos de la respublica ni a la

les et caligae.» Isid. Hisp., Reg.XII, 322-4; en CAMPOS, J.; ROCA MELIÁ, I. (eds.), Reglas monásticas de la España visigoda, Madrid, BAC, 1971. Sigamos por Fructuoso: «De cautela monachi: Cautela et moderatio et pudicitia et fides et sinceritas ornant habitum monachi. Duplex enim nullo modo esse debet famulus Xpi, sed veridicus et simplex et humilis (...)» Fruct. Bracc., Reg. X; en CAMPOS, J.; ROCA MELIÁ, I. op. cit. Para reglas monásticas en general, GIL, J., «La normalización de los movimientos monásticos en Hispania: reglas monásticas de época visigoda», Codex Aquilarensis, 10 (1994), pp. 7-20; VELÁZQUEZ, I., «Reflexiones en torno a la formación de un corpus regularum de época visigoda», Antigüedad y Cristianismo XXXIII (2006), pp. 531-567.

${ }_{45}$ Respecto a la adhesión a un pacto, como veremos, Fructuoso retoma al pie de la letra la idea de conferir estabilidad a la comunidad a través de este instrumento retomado de los ámbitos militar y jurídico. En referencia al peso de la regla, ambos le conceden primera importancia. Isidoro abre el juego a la posibilidad de cultivar reglas ya probadas de los padres, de las que la suya propia sería una destilación y un camino entre otros posibles. Fructuoso, por su parte, establece un vínculo distinto entre regla y comunidad: la regla distingue a las comunidades por él fundadas, las opciones de conversión son muchas pero de pretender adherir a un monasterio fructuosiano se debe obligatoriamente aceptar el camino ascético programado en la regla. La cita en Isidoro: (En relación a la suscripción a un pacto): «De conversis: Omnis conversus non est recipiendus in monasterio nisi prius ibi se scriptis sponderit permansurum.. Sicut enim ii qui ad saecularem promoventur militiam in legionem non transeunt nisi antea in tabulis conferantur, ita et ii qui in spiritalibus castris caelesti militiae sunt signandi nisi prius professione aut verbi aut scripti teneantur, in numerum societatemque servorum xpi transire non possunt.» Isid. Hisp., Reg. IV, 84-9. (En relación al respeto a la regla) «Praefatio: Plura sunt praecepta vel instituta maiorum qua sanctis patribus sparsim prolata reperiuntur. Quaeque etiam nonnulli altius vel obscurius posteritati tradiderunt, ad quorum exempla haec pauca nos vobis eligere ausi sumus ut sermone plebeio vel rustico quam facillime intellegatis quo ordine professionis vestrae votum retineatis. Praeterea quisque illam universam veterum disciplinam contendit adpetere, pergat quantum placet et arduum illum limitem adque angustum levigatum incedat; qui vero tanta iussa priorum exempla nequiverit in huius limitis disciplinam gressum constituat, ne ultra declinatus disponat nec dum declinatus adpetit inferiorem tam vitam quam nomen monachi perdat. Quapropter sicut illa praecepta priorum perfectum monachum reddunt ac summum ita faciunt ista vel ultimum. Illa custodiant perfecti, ista sequantur post peccatum conversi.» Isid. Hisp., Reg., 4-15. En Fructuoso: "Omnis conversus quum ad coenobium venerit et seque suscipi postulaverit, confestim in conspectu totius congregationis adductus sciscitabitur ab abbate utrum liber an servuus sit; utrum bona et spontanea voluntate an fortasse qualibet compulsus necessitate converti voluerit. Quumque eius spontaneam ad conversionem praevideret exsistere voluntatem neque quolibet eum condicionis nexu praevideret existere voluntatem neque quolibet eum condicionis nexu adscrictum esse praespexerit, accipiet pactum eius omnem suae professionis continentem originem, in quo etiam ita se isdem convertens alligabit, ut omnia se instituta coenobii mente devota profiteatur implere.» Fruct. Bracc., Reg. XXI.

${ }_{46}^{4}$ En Isidoro la preocupación por la formación intelectual es más precisa e insistente. Sin embargo, ésta está presente en ambos. Considerando a Isidoro: (...): «Propiis autem temporalibus oportet operare monachum et propiis orationibus lectionique incumbere; horas enim debet habere monachus congruas ad singula officia deputatas.» Isid. Hisp., Reg. V, 156-9. A Fructuoso: «De operatione: In operando haec ratio conservatur verno vel aestate. Dicta prima comoneantur decani a praeposito suo quale opus debent exercere, adque illi reliquos admonet fratres. Tunc demun ducto signo adsumtisque ferramentis congregantur in unum; factaque oratione pergent recitantes ad opus usque ad horam diei tertiam. Revertentesque ad ecclesiam tertia celebrata residentes locis suis student orationi sive lectioni. (...)» Fruct. Bracc., Reg. IV, 114-118.

47 Como hemos ya advertido, resulta remarcable las remisiones de Isidoro a otros ámbitos, como la milicia o la práctica jurídica, para consolidar su razonamiento. En esta cita, por afinidad del tema, Isidoro apela al registro jurídico: «De rebus monasterii: Abbate vel monacho monasterii servuum non liceat facere liberum. Qui enim nihil proprium habet libertatem rei alienae dare non debet. Nam sicut et saeculi leges sanxerunt, non potest alienari possessio nisi a proprio domino, ita et omne quod in monasterio in nummo ingreditur sub testimonio seniorum accipiendum (...)» Isid. Hisp., Reg. XX, 494-8. La misma cuestión en Fructuoso; como se notará, ya no hace referencia a lo jurídico sino directamente a la Escritura, gesto que busca patentizar la autonomía del campo: «De habitu vel vestimento monachorum: Nec quisquam e mo- 
solicitud de los reyes ${ }^{48}$. Sin embargo, una disciplina enfáticamente más rigorista ${ }^{49}$; la insistencia a la obediencia absoluta al abad ${ }^{50}$; y la inclusión de estos últimos en la categoría de los prelat $^{51}$ —operación que Isidoro no había realizado ${ }^{52}$ — nos advierten

nacis suum adserens dicat: codex meus, tabula mea vel reliqua, quod verbum, si de ore eius effugerit, paenitentiae subiaceat. Nec velut propria quilibet in monasterio habere videatur, sed sin illis sicut scriptum est omnia communia» Fruct. Bracc., Reg. XI, 241-4.

48 «III. De mensis: (...) Carnem cuiquam nec gustandi neque sumendi est concessa licentia. Non quod creaturam dei iudicemus indignam, sed quod carnis abstinentia utilis et apta monachis extimetur, servato tamen moderamine pietatis erga aegrotorum necessitudines vel longe proficiscentium qualitates; ut et volatilium esibus infirmi sustentur, et longiquo itinere destinati, si aut a principe vel episcopo sperantur pro benedictione et obedientia, degustare non metuant, servantes apud se de reliquo continentiam consuetam. (...)» Fruct. Bracc., Reg. III, 91-7.

49 Comparando el tema en un mismo rubro para que se advierta con claridad la diferencia -en este caso, el tratamiento de los castigos - lo notable es la severidad del tono en Fructuoso y el énfasis en el castigo como remedio para el alma. Isidoro prevé límites a esto. De acuerdo a Fructuoso: «De delictis: Omnes actus sive occasionum necessitudines suo semper necesse est ut monachus referat patri et ex illius cognoscat discretione vel iudicio quod adtendat; cogitationes, revelationes, inlusiones et neglegentias proprias seniori nullus obcelet verecundia vel incuria faciente vel contumacia perurguente, sed semper huiusce modi vitia cum lacrimis et compuctione cordis adque humilitate verissima abbati, praeposito sive probatis senioribus revelanda sunt, et consolationes orationes et castigationes, sive etiam exorationes eis operis castigandum.» Fruct. Bracc., Reg. XII, 255-262. Considerando el mismo tema en Isidoro: «De culpa indulgenda vel culpati correctione: Qui verbo in fratrem peccaverit, si statim reminiscens ad veniam poscendam fuerit inclinatus, percipiat ab eo indulgentiam. Qui autem aut non petit aut non ex animo percipit in colatione deductus iuxta excessum iniuriae congrue subiaceat disciplinae. Qui sibimet invicem convicia obiciunt, si iterum invicem sibi celeriter laxando ignoscunt ii ab alio indicandi non sunt quia pariter sibi veniam dare festinaverunt, si tamen excedere in semetipsos frequentius non praesumant. Qui sponte culpam confitetur quam gessit veniam promereri debet quam expetit; orent igitur pro eo et confestim si levis culpa est postulata indulgentia praebeatur. Qui pro gravi vitio saepe excommunicatus emendari neglexerit tamdiu damnationi subiaceat quousque vitia inolita deponat, ut quem semel inlata animadversio non coercuit, frequens severitas censeat emendandum. Quamvis fraquentium gravissimorumque vitiorum varagine sit quisque inmersus, non est tamen a monasterio proiciendus, sed iuxta qualitatem delicti coercendus, ne forte qui poterat per diuturna tempora paenitudinem emendari, dum proicitur ore diaboli devoretur.» Isid. Hisp., Reg. XVI, 386-401. Para la ideología de Fructuoso, cf. AMARAL, R., «O ideal eremítico no monacato de Sâo Fructuoso de Braga», Theologica, 38 (2003), pp. 107-17.; CANTERA MONTENEGRO, S.-RODRÍGUEZ de la PEÑA, A., «Conciencia hispánica y tradición monástica en la Vita Fructuosi», en Cuadernos de estudios gallegos, LIV, no 120 (2007), particularmente pp. 79 y ss.; DÍAZ Y DÍAZ, «Fructuoso de Braga y el Bierzo», Tierras de León, 8 (1967), pp. 53-52. Una comparación entre la regla isidoriana y la fructuosiana en GIL, J., «La normalización...», op. cit., pp. 14.

50 «IV: De obedientia et sessione monachi: (...) Obedientia praeceptum est regulae ut impossibilibus quoque rebus opere adque adfectu ostentetur et teneatur usque ad mortem, videlicet sicut et Xps factus est patri obediens usque ad mortem; simili quoque studio et patientiae virtus est observanda ut nusquam nec odio violetur nec iniuria, nec contumeliis omittatur, se din sustentatione et tolerantia roboretur (...)". Fruct. Bracc., Reg. IV, 172-7.

51 «De abbate vel praeposito: (...) Quique sic egentibus atque pauperibus pareat ut ministrum se et non praelatum tantum Xpi visceribus recognoscat. (...)» Fruct. Bracc., Reg. XIX, 377-9.

52 Efectivamente, en el lugar donde Isidoro utiliza más asiduamente la categoría de praelatus es en las Sententiae. De praelatis es el rótulo que da título al capítulo XLVIII del libro III. La primera sentencia allí indica que esa palabra puede ser utilizada tanto para los dignatarios seculares como para los eclesiásticos («De praelatis: Vir iustus aut omni potestate saeculari exuitur aut, si aliqua cingitur, non sub illa curuatur ut superbus tumeat, sed eam sibi subicit ut humilior innotescat. Probatur autem hoc apostolico exemplo, qui datam sibi potestatem etiam nec ad hoc usus est quod licebat, sed, dum possit utere, licita abnuit seseque ut pavuulum in medio eorum quibus praeerat ostendit.» Isid. Hisp., Sent. III, XLVIII, 1). Visto en el contexto, Isidoro viene hablando principalmente de los obispos y eventualmente de los presbíteros, a quienes desde el capítulo XXXIII, empleando la categoría de praepositis Ecclesiae, define como los encargados de la administración del orden eclesiástico-elemento que excluiría a los abades («De praepositis Ecclesiae: Vir ecclesiasticus et crucifigi mundo per mortificationem propriae carnis de 
un deslizamiento de perspectiva. El programa de Fructuoso retoca efectivamente el vínculo planteado por Isidoro entre salvación, ecclesia y respublica. Si para el hispalense la orientación de los rectores virtuosos constituía un camino de salvación, la posibilidad de ser contados entre el resto de los justos, para el del Bierzo esto mismo necesitaba del trabajo insoslayable de los monjes. Las murallas del monasterio circunscribían un foco de santidad, una garantía de pureza y de oración, y coadyuvaban materialmente a convertirlo en una mediación indispensable entre la divinidad y el pueblo inconstante ${ }^{53}$. El proyecto fructuosiano resultaba más vertical y jerárquico aún de lo que proponía Isidoro: si para el hispalense la mediación entre Dios y su grey era la jerarquía de reyes y obispos, el del Bierzo añadía a esta cadena la instancia de los que habían renunciado al mundo ${ }^{54}$. Anotemos además que, en el terreno de las prácticas, el diseño de Fructuoso recibió el apoyo caluroso de la nobleza $^{55}$. Estas operaciones por supuesto se refuerzan y legitiman a través de un recuento de milagros prodigados por el santo en tiempo presente ${ }^{56}$.

bet, et dispensationem ecclesiastici ordinis, si ex Dei voluntate provenerit, nolens quidem, sed humilis gubernandam suscipiant.» Isid. Hisp., Sent. III, XXXIII, 1). La comparación con el Apóstol que realiza en la sentencia III, XLVIII, 1, unida a la reflexión sobre la realeza que capea todo el capítulo XLVIII apunta más a una inclusión de los obispos en la categoría de praelati que a la de los abades (para una construcción de la ideología monárquica de los obispos, principalmente HALL, S., «Institutions in the pre-Constantinian ecclesia», en MITCHELL, M.; YOUNG, F., The Cambridge History of Christianity, volume 1, Origins to Constantine, Cambridge, Cambridge University Press, 2008.) La inclusión de los abades en la jerarquía queda oficializada en el reino visigodo a partir del concilio VIII de Toledo, convocado en 653 por Recesvinto. Con anterioridad a este concilio, los abades concurren pero en representación del obispo de su diócesis, como lo demuestra el caso del abad Crispinus, que concurre en nombre del obispo Neufredus de Olysipo (Lisboa) al concilio VII de Toledo de 646. Estas fechas coinciden con la actividad de Fructuoso. En el análisis que Niermeyer otorga de la palabra praelatus incluye directamente esta última acepción que considera a los abades miembros de este orden (cf. NIERMAYER, J.F., Mediae Latinitatis Lexicon Minus: Lexique Latin Medieval-Francais/Anglais/a Medieval Latin-French/English Dictionary, Leiden, Brill, 1976, p. 834.)

53 «De primis conversorum: (...) Monachi in monasterio sancte et pudice adque honeste viventes persistant. Nihil foris claustris coenobii sine abbatis vel praepositi mandato peragant, nec liceat monachum foris claustris coenobii proprii longius evagari, nisi vicino dumtaxat hortulo, vel pomerio cum benedictione senioris» Fruct. Bracc., Reg. XXII, 436-40. Para las condiciones que debía cumplir un monasterio para asumir el rol de garantía de pureza ortodoxa y oración, vid DÍAZ, P. «Monasteries in a peripheral area: seventh-century Gallaecia», en De JONG, M.; THEWS, F., van RHIJN, C., Topographies of Power in the Early Middle Ages, Leiden, 2001, especialmente p. 337. Para la función de la muralla como instrumento de delimitación física de un espacio preciso vid. MARTIN, C., op. cit. pp. 52 y ss.

54 «Beatissimus vero Fructuosus, cumque exemplo suo excellentissimae sanctitudinis coruscante splendiflua claritate cunctam inluminasset Spaniam, atque per singulas diversarum regionum congregationes monachorum ad instar innocui cordis sui perfectorum enutrisset agmina discipulorum, ita ut usque hodie nuperrime convertentes, per ordinem priorum discedentium sanctorum seriem invicem suscipientes, illius antiqua quasi hodierna floreant exempla, et usque in finem mundi fructus eius operis gignat, semper innovetur memoria, atque in regno caelorum, gregis ipsius multiplicetur quotidie agmina copiosa" Vit. S. Fruct. XVI, 1-10.

55 «[Benedicta] nempe spiritualibus studiis diligenter indepta, cumque eius fama per diversam terram fuisset laudabiliter propalata, tantus desiderii ardor inflammavit ceteras diversorum filias, ut undique alacriter conflueret eximia puellarum caterva, ita ut intra breve temporis spatia octuagenarius in congregatione numerus sanctarum virginum compleretur. Quibus in alia solitudine, more solito, construit monasterium. Tanta itaque in utroque sexu almifica florebat sanctitas atque eximia crescebat fama perfectionum, ut viri cum filiis suis ad sanctam se converterent congregationem monachorum, matronas vero eorum cum filiabus, suis sancto se sociarent consortio puellarum.» Vit. S. Fruct. XV, 19-29.

56 «Nunc igitur non prisca, sed moderna; non vetera, sed novella; non vanis quibuslibet fabulis facta, sed miracula veritatis indicio declarata!» Vit. S. Fruct. XII, 1-3. 
En síntesis, paralelamente al ajuste del programa isidoriano que los círculos episcopales venían realizando, otros sectores ensayaban nuevas fórmulas para dar respuesta al cambio de coyuntura. La diferencia entre unos y otros es que estos últimos diseños superponían nuevos mediadores, elemento que alteraba la condición monopólica que la elite se aseguraba en el proyecto isidoriano.

\section{JULIÁN Y VALERIO:}

La coyuntura que se extiende entre 680 y 700 vuelve a presentar nuevos desafíos. El imperio acababa de sobreponerse con dificultad al segundo asalto a Constantinopla, se debatía entre luchas facciosas, presiones del ejército, senado e institución imperial y se encaminaba a la reforma por temas. Desde 661, la dinastía Omeya por su parte se embarcaba en la organización de un estado territorial al modo romano y sasánida, intentando erguirse en árbitro entre los diferentes grupos. Por razones militares y políticas, el impulso militar se dirigió con mayor fuerza hacia occidente: en 670, efectivamente, fundaron la plaza fuerte de Kairouan, y en 698 se hicieron con la provincia de Ifriqiya, consolidando la presencia hasta el frente atlántico.

Preocupante... y sin embargo, el nodo más importante para los intelectuales visigodos no estaba aquí. Como lo demuestran las propias fuentes, el centro de pensamiento es la propia dinámica del reino, atrapada en dos sucesiones regias de carácter irregular: la de Ervigio (680-7) y Égica (687-702). Habiéndose hecho del trono mediante la utilización en provecho propio de la divisa rex eris si recte facias de Isidoro, estos monarcas ciertamente estaban ansiosos por desplegar lo más espectacularmente posible todo el catálogo de virtutes principescas: la clemencia, la justicia, la paciencia ${ }^{57}$. Lejos de evidenciar debilidad o falta de iniciativa monárquica, la remanida repetición de leyes, la promulgación histérica de medidas antijudías, la convocatoria a concilios, las amnistías jurídicas y fiscales señalan una búsqueda de mayor protagonismo por parte de estos monarcas y la promoción de un patrón de relaciones aún más piramidales. No olvidemos que es Ervigio quien, en el concilio XII de Toledo, explicita la idea de que después de la fidelidad debida a Dios, se debe observar la obediencia debida al rey ${ }^{58}$.

57 A manera de ejemplo: «De tributorum principali relaxatione in plebe: Tertii ordinis gloriosae insinuationis occursu liberalitas principalis longe lateque diffussa nostro se invexit coetui agnoscenda, quae sicut ex puro fonte regiae provisionis processit, ita synodialis conventus debet sanctione praestingi. Et ideo religiosi principis nostri Ervigii regis affectus in toto gentis suae ambitu usquequaeque porrectus de virtute in virtute quodammodo gradiens et quasi quibusdam passibus ad meliora conscendens, hoc per stilum regiae auctoritatis decrevit, ut omne tributum praeteritorum annorum usque in anno primo regni sui, quod in privatis sive in fiscalibus populis reiacet, absolutionis perpetuae debeat sanctione laxari, et tantum de ipsis tributis praecipiens thesauris publicis exhiberi quae exacta et non illata fuisse constiterint. Quod pietatis beneficium admirantes non solum vigorem gloriosae definitioni eius apponimus, sed et perpetuae excommunicationi eum qui contra hoc venerit subiciendum esse sancimus. " Tol. XIII, III, 283-299.

58 «Et ideo soluta manus populi ab omni vinculo iuramenti, quae praedicto viro Wambae dum regnum adhuc teneret alligata permansit, hunc solum serenissimum Ervigium principem obsequendum grato ser- 
Esta es precisamente la coyuntura en la que escribe Julián, arzobispo de Toledo entre 679 y 690 . Heredero de la tradición isidoriana, este prelado nacido en la Ciudad Regia fue discípulo directo de Eugenio II de Toledo, quien lo educó en los valores intelectuales del respeto por la erudición y el cuidado por la formación letrada y moral del clero ${ }^{59}$. No sólo la finura de sus reflexiones teológicas, sino la preocupación por dotar al sacerdocio de herramientas intelectuales idóneas remiten de forma directa al viejo tronco isidoriano ${ }^{60}$.

En la misma línea que Isidoro y Tajón, Julián reconoce la importancia de atender la marcha de los asuntos públicos ${ }^{61}$. En tanto metropolita de Toledo, considera que propiamente es su responsabilidad mayor vigilar el desempeño del oficio regio a la luz de los criterios fundados por Isidoro, la divisa rex eris ${ }^{62}$. Esta idea de su misión pastoral explica, por un lado, su protagonismo en la destitución del rey Wamba en 680; y por otro la redacción de su célebre Historia, en donde despliega una reflexión profunda acerca de la monarquía y los peligros que giran alrededor de ella ${ }^{63}$.

vitii famulatu sequatur et libero, quem et divinum iudicium in regno praeleelegit et decessor princeps successurum sibi instituit, et quod superest quem totius populi amabilitas exquisivit. Unde his praecognitis atque praescitis serviendum est sub Deo caeli praedicto principi nostro Ervigio regi cum pia devotione» Tol. XII, I.

59 «Formado por el mismo Eugenio, aparece poco después Julián de Toledo. La orientación se hace aquí más personal: su gran cultura, sus lecturas verdaderamente asombrosas hacen de este personaje un segundo Isidoro (...) DÍAZ y DÍAZ, M., "Cultura visigótica del siglo VII», en De Isidoro al siglo XI. Estudios sobre la vida literaria peninsular, Barcelona, El Albir universal, 1976, p. 46.

${ }^{60}$ El ars grammatica - obra que probablemente no sea de su autoría directa, pero sí de producto de su inspiración- da testimonio cabal de esto: «Latinas autem linguas quattuor esse quidam dixerunt, id est, priscam, latinam, romanam et mixtam: prisca est quam vetustissimi Italiae sub lano et Saturno sunt usi, incondita, ut se habent carmina Saliorum; latina, quam sub latino et regibus Tusci et ceteri in Latio sunt loculi, ex qua fuerunt duodecim tabulae scriptae; romana quae post reges exactos a populo romano gesta est, uam Nevius, Plautus, Ennius, Vergilius, poetae, et ex oratoribus, Gracchus, et Cato, et Cicero, vel ceteri effuderunt; mixta, quae post imperium latius promotum simul cum moribus et hominibus in Romanam civitatem inrumpit, integritatem verbi per soloecismos et barbarismos corrumpens.» Iul. Tol., Ars gramm., II, 14, 115-125; en MAESTRE YENES, M. (ed.), «Ars Iuliani Toletani episcopi. Una gramática latina de la España visigoda», Vestigios del pasado, Toledo, Publicacines del Instituto provincial de investigaciones y estudios toledanos, 1973.

61 «Ligado igualmente a los conceptos escatológicos, pero también a la reinterpretación literal del Antiguo Testamento, se halla un fenómeno que caracteriza la producción de Julián tanto como lo que conocemos de su actuación política y su actitud frente a los monarcas y la sede romana: este fenómeno es la configuración de una moral orientada a la acción, a la solución de los problemas de modo tajante» GARCÍA HERRERO, G., «El reino visigodo en la concepción de Julián de Toledo», Antigüedad y Cristianismo, XII (1995), pp. 413 y ss. Del mismo autor, «Julián de Toledo y la realeza visigoda», Antigüedad y Cristianismo, VIII (1991), pp. 201-256.

62 «L Historia Wambae est d'abord l'exaltation du rex gothorum», TEILLET, S., Des Goths à la Nation gothique. Les origines de l'idée de nation en Occident du Ve au VIle siècle, Les Belles Lettres, París, 1984, p. 586.

63 Para la Historia Wambae, MARTínEZ PIZARRO, J. (ed.), The story of Wamba, Julian of Toledo's Historia Wambae regis, The Catholic University of America Press, Washington, 2005; GARCíA LÓPEZ, Y., «La cronología de la «Historia Wambae«», Anuario de Estudios medievales, 23 (1993), pp. 12139; DE JONG, M., «Adding insult to injury. Julian of Toledo and his Historia Wambae, en HEATHER, P. (ed.), The visigoths from the migration period to the VIIth. Century. An ethnographic perspective, San Marino, Boydell Press, 1999, pp. 373-402; más general, HILLGARTH, J., «Historiography in visigothic Spain», XVII Settimana di Spoleto, Spoleto, Centro italiano di studi sull'alto medioevo, CISAM, Spoleto, 1970. 
Si queremos evitar la ira divina: Impacto y vicisitudes del proyecto eclesiológico...

En un grado todavía más erizado que Tajón, Julián se hace eco de los rumores apocalípticos de su época64. Aparentemente refutando una tesis corriente en las aljamas que negaba el carácter mesiánico de Cristo sobre la base de cálculos milenaristas, el obispo de Toledo tranquiliza a sus fieles demostrando que Cristo nació efectivamente en el sexto milenio —remitámonos a la fecha de 5325 que había anotado Julián ${ }^{65}$ - y que por lo tanto era el Mesías; que desde la creación a su actualidad habían transcurrido 6011 años —comprobación de la sexta edad-; y finalmente que el crítico año 6000 ya había pasado de largo y el mundo seguía sin haberse derrumbado ${ }^{66}$. Como podemos advertir, elementos relevantes del programa isidoriano - la tradición erudita, la relación con los asuntos públicos, una apocalíptica tranquilizadora - son retomados después por el arzobispo de Toledo para dar cuenta de una nueva actualidad ${ }^{67}$.

El ajuste fundamental que Julián opera para adecuarse a la coyuntura es la consolidación del carácter primado de la silla toledana con respecto al resto de los metropolitas y obispos diocesanos. Recordemos que bajo su gobierno Toledo se asegura el control de los nombramientos episcopales y, por ende, el reconocimiento jurídico de la supremacía ${ }^{68}$. Esta medida modifica al programa isidoriano en

64 DEL VALLE RODRíGUEZ, C., «Julián de Toledo», en DEL VALLE, C., op.cit.; HILLGARTH, J., «Escathological ...».

65 «Ab initio itaque mundi usque ad tempus nativitatis Christi, quando quadragesimus primus annus Octaviani Caesaris fuit, eveniunt anni VCCCCXXV. lam vero residuus annorum numerus a tempore nativitatis Christi usque in praesens, in promptu est unicuique, et scire si volet, et supputare si placet, assumptis videlicet annis secundum eram ab ipsa Domini incarnatione» Iul. Tol. De compr., III, X, 104-112; en HILLGARTH, J. (ed.), Sancti Iuliani Toletanae sedis episcopi opera, Pars I, CCSL CXV, Turnoholt, Brepols, 1976.

66 «Nunc autem acclamatur eram esse DCCXXIIII. Detractis igitur XXX et VIII annis, ex quo era inventa est, usque ad nativitatem Christi, ressuidi sunt anni DCLXXXVI. «Reliquum igitur huius sextae aetatis tempus», id est, a praesenti die usque in horam ipsam finis saeculi, quod annorum spatiis protendatur, «soli Deo cognitum est». At nunc sit soli gloria ipsi unigenito Christo Dei filio, per quem repudiata interim manifesta patescit opinio illa vestra vanissima, qua et sextam adhuc aetatem saeculi expectatis, et saeculum istud in sex millibus tantum annis stare confingitis, quos iam et ipsos transactos esse probatis, si studiosius attendatis. Repetendum est igitur quod audistis.» lul. Tol. De compr., III, X, 111-124. Un análisis de los cálculos milenaristas de Julián de Toledo en LANDES, R. «Lest the millenium be fulfilled: apcalyptic expectations and the pattern of western cronography (100-800 CE), en VERBEKE, W.; VERHELST, D.; WELKENHEYSEN, A., The use and abuse of Escathology in the Middle Ages, Lovaina, Leuven University Press, 1988, especialmente p. 173. Una perspectiva del pensamiento antijudaico de Julián en CORDERO NAVARRO, C., «El problema judío como «visión del otro» en el reino visigodo de Toledo: revisiones historiográficas», En la España medieval, 23, 2000, especialmente p. 13.

67 «Es cierto que Ildefonso y Julián perseguían, como había predicado Isidoro, y siguiendo su ejemplo, una acción pastoral concertada y tradicional que busca en las fuentes antiguas la solución para los problemas nuevos, un poco con la obsesión de reducir éstos, a su vez, a los viejos y constantes problemas de la vida espiritual» DÍAZ y DÍAZ, M., «Obra literaria de los obispos toledanos», en De Isidoro... pp. 107.

68 «De concessa Toletano pontifici generalis synodi potestate, ut episcopi alterius provinciae cum conniventia principum in urbe regia ordinentur: Illud quoque collationi mutua decernendum nobis occurrit, quod in quibusdam civitatibus, decidentibus episcospis propriis dum differtur diu ordinatio succesoris, non minima creatur et officiorum divinorum offensio et ecclesiasticarum rerum nocitura perditio. Nam dum longe lateque difuso tractu terrarum conmeantum impeditur celeritas nuntiorum, quo aut non queat regiis auditibus decidentis praesulis transitus innotesci aut de succesore morientis episcopi libera principis electio praestolari, nascitur saepe et nostro ordini de relatione talium dificultas et regiae potestati, dum consultum nostrum pro subrogandis pontificibus sustinet iniuriosa necessitas. Unde placuit omnibus pontificibus Spa- 
dos sentidos: en primer lugar, restringe a un círculo minúsculo la participación en la gestión regular del poder; en segundo lugar, institucionaliza el liderazgo: si Isidoro concebía que el peso en el interior del clero debía ganarse sobre la base de erudición y servicio, Julián definía esta elección a través de nombramientos ritualmente legítimos. Para vigilar con solvencia mayor el desempeño del rey, el recurso era estabilizar los controles fortaleciendo al obispo de la ciudad regia. De esta manera se repetía el esquema asentado en las Sagradas Escrituras, en el cual el mejor supervisor de Saúl fue Samuel ${ }^{69}$. Como podemos advertir, este no es la estructura que diseña Isidoro para el clero y para el regnum gothorum: constituye una respuesta a los cambios de situación y de relaciones de fuerza. Sin embargo, este ajuste se realiza manteniendo los pivotes fundamentales del proyecto de Isidoro. Los monjes no constituyen parte indispensable de la mediación.

Este rico panorama de cambios y respuestas se completa con la intervención de Valerio, eremita del Bierzo contemporáneo a Julián, que aproximadamente vivió entre 630 y $695^{70}$.

En tiempos de Valerio, la práctica eremítica -es decir, el tipo de ascesis que rompe voluntariamente con los marcos de referencia de la respublica y que toma como modelo a los padres tebanos- conocía ya una larga trayectoria en la península; lo que hace Valerio, en todo caso, es buscar legitimar esa elección y el tipo de sociedad que propone a través del expediente escriturístico ${ }^{71}$.

niae et Galliae ut, salvo privilegio uniucuiusque provinciae, licitum maneat deinceps Toletano pontifici quosquumque regalis potestas elegerit et iamdicti Toletani episcopi iudicium dignos esse probaverit, in quibuslibet provinciis in praecedentium sedibus praeficere praesules et decidentibus episcopis eligere successores; ita tamen ut quisquis ille fuerit ordinatus, post ordinationis suae tempus infra trium mensium spatium proprii metropolitani praesentiam visurus accedat, qualiter eius auctoritate vel disciplina instructus condigne susceptae sedis gubernacula teneat. Quod si per desidiam aut neglectu quolibet constituti temporis metas excesserit, quibus metropolitani sui nequeat obtutibus praesentari, exconmunicatum se per omnia noverit, excepto si regia iussione impeditum se ese probaverit. Hanc quoque definitionis formulam, sicut de episcopis ita de ceteris ecclesiarum rectoribus placuit observandam.» Tol. XII, VI.

69 Hillgarth, la editora de las obras de Julián, resalta con tino que los textos a los que Julián reenvía en la Historia Wambae son el salmo 88 y el libro I de Reyes, que en la Vulgata corresponde a I Samuel. Cf. HILLGARTH, J., «Historiography..», pp. 300. Petit a su turno también lo hace: cf. PETIT, C., Iustitia Gothica. Historia social y teología del proceso en la Lex Visigothorum, Huelva, Universidad de Huelva, 2001, pp. 407-411.

70 Valerio, a diferencia de otros intelectuales visigodos como por ejemplo Tajón, ha recibido bastante atención por parte de filólogos e historiadores: el ya clásico tomo XLVIII de la revista Helmantica, dedicado por entero al análisis de su obra, así lo muestra. En general, para su producción intelectual DÍAZ y DÍAZ, M., Valerio del Bierzo. Su persona, su obra, Centro de Estudios e Investigaciones «San Isidoro», León, 2006; idem, DÍAZ y DÍAZ, M., «Sobre la compilación historiográfica de Valerio del Bierzo», Hispania Sacra, VI no 7, 1951, pp. 3-25; ORLANDIS, J., «Algunas consideraciones en torno a la circunstancia histórica de Valerio del Bierzo», Helmantica, XLVIII (1997), pp. 153-64; MARTIN, J.C., «¿Valerio en Compludo? Examen crítico de los Opúsculos autobiográficos (CPL 1282-1284) y de las visiones del más allá (CPL 1277-1279) de Valerio del Bierzo», Veleia, 23 (2006), pp. 327-38, entre otros.

71 La bibliografía sobre eremitismo antiguo en la península es vastísima: el grupo de investigadores coordinados por A. González Blanco viene publicando en Antigüedad y Cristianismo artículos de interés sobre este tema desde hace tres décadas, e inclusive le ha dedicado volúmenes enteros, como el de 1998. Para citar sólo algunos trabajos conocidos, DÍAZ Y DÍAZ, M., «Eremitical Life in Visigothic Spain», Classical Folia (1969), pp. 209-227; CORULLÓN, I., «El eremitismo en las épocas visigoda y altomedieval a través de las fuentes leonesas», Tierras de León. Revista de la Diputación Provincial, 26 nº 64 (1986), 
Si queremos evitar la ira divina: Impacto y vicisitudes del proyecto eclesiológico...

Erudición y escritura son dos instancias que este eremita retoma de la herencia isidoriana; pero hasta allí podemos extender los puntos de contacto entre un proyecto y otro. En efecto, el diseño de Valerio se constituye en las antípodas del de Isidoro.

En el Ordo queremoniae, Valerio inicia la defensa de su propia vida aludiendo a su origen en la ciudad de Astorga, pero - a diferencia de lo que acostumbraba a hacer la hagiografía con la narración de sus héroes- este eremita no hace referencia a linaje alguno: no debe nada a las coordenadas tradicionales que marcan pertenencia a la sociedad; su autoridad descansa en la elección que Dios ha hecho de él, concediéndole una gracia y un poder por fuera de las pautas ordinarias $^{72}$.

Invirtiendo el legado isidoriano, Valerio reconoce legitimidad a obispos, clérigos, seniores y al mismísimo rey en la medida que éstos le reconozcan primeramente autoridad a él ${ }^{73}$ : de no ser así, o son abiertamente ignorados o tachados de prac-

pp. 23-36. Desde el punto de vista arqueológico, AZKÁRATE GARAI-OLAUN, A., «El eremitismo de época visigótica. Testimonios arqueológicos», Codex Aquilarensis. Cuadernos de Investigación del monasterio de Santa María la Real, 5 (1991), pp. 141-79. Para los rasgos fundamentales del movimiento sugerimos RUBENSON, S. "Ascetism and monasticism I: Eastern» y DUNN, M., "Ascetism and monasticism II: Western", en CASIDAY, A.; NORRIS, F., The Cambridge History of Christianity. Vol II: from Constantine to c. 600, Cambridge, Cambridge University Press, 2007; LEYSER, C., Authority and ascetism from Augustine to Gregory the Great, New York, Oxford University press, 2001. VALANTASIS, R. "A theory of the Social function of Asceticism» en WIMBUSH, V. (eds.) Asceticism. Oxford, Oxford University Press, 1998, entre otros. Para un panorama muy general acerca de la difusión de esta práctica en el orbe mediterráneo MOLINA GÓMEZ, J., «Recorrido por la geografía del monacato rupestre. Para una interpretación histórica». Antigüedad y Cristianismo XXIII (2006), 649-75.

72 «Dum olim ego, indignissimus peccator, Asturiensis provinciae indigena, intra adolescentie tempora mundialibus inlecebris occupatus, lucrisque terrenis iniens, vanis disciplinis intentus, per infimi saeculi tenebras cura eorum frena laxarem, subito gratie divine desiderio coactus pro adipiscenda sacre religionis crepundia toto nisu undivagi seculi fretum adgrediens, velut navigio vectans, ad Complutensis cenobii litus properans transmeare inmensi desiderii ardore succensus atque futuri iudicii timore perterritus, confidens per conversionis itinere tandem ad lucem pertingere veritatis, sed ideo mundani maris fluctibus oppressus, atque ex diabolico saepe infestante flabro dire tempestatis procellis expulsus desideratum non valui pertingere portum.» Val. Berg.,Ordo querimonie prefati discriminis. 1, 1-16, en DÍAZ y DÍAZ (ed.), Valerio del Bierzo..., op. cit.

${ }^{73}$ Un ejemplo: «24. Ipso quoque tempore, licet providentia divina, que semper pro pauperorum suorum miseria sollicita adhibeat cura, ne ego miserrimus ab omni consolationis presidio relinquerer destitutus, de terra nativitatis mee sollicitavit ad timorem suum mici proximum, fratris mei Montani filium, nomine Johannem, qui conpucto corde veniens reliquit servitium regis, atque uxorem et filios, vel omnia que habebat, et convertens cum famulo suo Evagrio se toto corde dominico mancipavit servitio, qui nunc usque que utrisque cellulis necessaria sunt fideliter elaborans ministrat. Nam adiutus a Domino qui eum sancti altaris ipsius iussit esse ministrum, vineas in eodem deserto, hortum olerum, et multas pomiferas diversi generis plantavit arbusculas atque domicilii fundavit habitacula; et cetera quae hic vel illi necessaria sunt, quotidie nititur, ope Domini, perficere, et in his desiderat usque ad finem vitae suae permanere.

25. Post crebras videlicet inimico impediente penuriae contritiones, atque amarissimas et tristes dispersionis desolationes, illa sempiterna pietas, que non vult facturae sue perditionem, tribuit infelicitati mee post quadraginta duorum continuo annorum contrictione aliquantulum quietis, cupitam consolationem et remedium. Insuper compuxit corda fidelium suorum ad misericordie pietatem: gloriosi principis, pontificum, caeterorumque Christianorum, qui largiflua in mea egestate operati sunt mercede, quam recipiant centumpliter Domino in hereditate celeste (...)» Val. Berg., Replicatio sermonum a prima conversione 24, en DíAZ y DíAZ,(ed.) Valerio del Bierzo..., op. cit. 
ticar contubernio con el diablo ${ }^{74}$. La verdadera autoridad no deviene de ritos, jerarquías o instancia institucionalizada alguna. Emana de la elección inescrutable de Dios y se deja advertir a través de la práctica ascética radical y de la intervención divina ${ }^{75}$. Valerio no promueve la desaparición de las autoridades tradicionales de la sociedad humana, antes bien brega porque éstas se pongan al servicio de los tocados por Dios.

Como podemos advertir, el proyecto valeriano modifica sustancialmente el modo de organizar la jerarquía: colocando como centro a la autoridad carismática, todo gira alrededor de este mediador único entre la divinidad y el resto de los mortales. En un artículo ya clásico, Collins revisa la idea de rubricar los textos de Valerio en términos de biografía personal ${ }^{76}$ : desde el punto de vista que acá defendemos, las intervenciones de este eremita del Bierzo forman parte de una forma diferente de concebir la sociedad, erizada por la necesidad de arrepentimiento y penitencia y por el postulado de la inminencia del juicio final. Este proyecto se diferencia no sólo de la postura de Isidoro, sino de los ajustes que ha recibido su legado y del diseño fructuosiano también. Una década antes de la llegada de los árabes, como podemos advertir, circulan en el reino visigodo proyectos que apuestan a desorbitar el lazo social instituido; y a encauzarlo de otro modo.

74 «5. Quum hec omnia prolixo iam tempore, opitulante Domino, tolerarem post aliquantorum annorum intervallo, tandem christiana videlicet miseratio pietate conmota, cepit se ibidem diversa utrumque sexu vulgi caterva confluens glomerare mici quoque infelici adiutorium prebere, obsequium inpendere vel stipendia ministrare. Quumque iam summa necessitas suffragante Domini pietate verteretur in voluptate, illico insurgens quidam vir barbarus, valde lubricus et cunctis levitatibus occupatus, Flainus nomine, eiusdem baselicule presbiter, antiqui hostis stimulis instigatus, invidie facibus magisque succensus, sicut mos pravorum est invidere aliis quod ipsi habere non adpetunt, eiusdem invidie tenebris cecatus, insaniens cepit adversus pusillitatem meam odia machinare atque crebra pretendere inpedimente sepeque iacturam incutere. Quum vero quandoquidem ad eundem locum conveniebat cute teterrima, sicut scriptum est: "frons piecea, nigriore proprio depromit amictu" truculentus velut saevissima bestia frendens, magis pro contumelia subversionis meee ad eundem locum accedebat quam ut pacem caritatis aut misericordiae pronecteret pietatis.» Val. Berg., Ord.Quer. 5. Un análisis de esta descripción en COLLINS, R., «The "autobiographical" works of Valerio of Bierzo. Their structure and purpose», Antigüedad y Cristianismo III (1986), pp. 428. Un ejemplo en donde el rey está involucrado en una operación en contra de Valerio en Val. Berg., Ord.Quer. 7.

75 «28. Unde infelicitas mea non cessat pium deprecare Dominum ut mici usque ad ultimum vite presentis occursum tribuat perpetuum de sevissimo hoste victorie triumphum, atque cunctorum malitias extinguat facinorum, et hunc quem mici pietas eius novissime concessit, non permittat usque ad mortem derelinquere locum.

29. Quia tantus existit congruentissime quietis ad instar paradisi aptissimus locus, ut etiam licet, ut supra sum locutus, sit eminentissimorum montium munitione circumseptus, nullius tamen instet tetrium umbrarum opacitate fuscatus, nisi luciflui splendoris venustissimo decore conspicuus atque vernatissimi viroris eximia amenitate fecundus, procul a mundo remotus, nullarum secularium actionum tumultibus neque feminarum occursibus infestatus, ut cunctis liquido patescat pro adipiscendo perfecte sanctitudinis culmine fidelibus a mundanis inlecebris commertiisque recedentibus a Dominus esse preparatus. Hec intuens inimicus et per ypocrisin sibi subjectis fideles Dei expellere conatur.» Val. Berg., Ord.Quer. 11. Para la relación con las autoridades instituidas, DÍAZ MARTÍNEZ, P.; FERNÁNDEZ ORTíZ de GUINEA, L., «Valerio del Bierzo y la autoridad eclesiástica», Helmantica, XLVIII no 147 (1997), pp. 19-36; PÉREZ SÁNCHEZ, D., «Poder religioso y realidad social en la obra de Valerio del Bierzo», Helmantica, XLVIII $n^{\circ}$ 147 (1997), pp. 165-82.

76 COLLINS, op. cit. Para los siglos posteriores, en relación a los patrones literarios cultivados por los eremitas de La Rioja GONZÁLEZ ECHEGARAY, J., «Sobre el contexto literario-teológico de los columbarios de La Rioja», Antigüedad y Cristianismo XXIII,(2006), pp. 677-84. 


\section{CONCLUSIONES}

La perspectiva de trabajo escogida ha puesto en una misma serie a intelectuales visigodos enrolados en generaciones sucesivas, expuestos por ende a situaciones históricas diferentes y, dentro de cada coyuntura, representando tradiciones variadas. Este enfoque permite advertir con mayor facilidad tres grandes cuestiones.

En primer lugar, la centralidad y vitalidad del proyecto isidoriano, retomado no sólo por los metropolitas de Toledo sino por los mejores exponentes de las escuelas regionales. El secreto de su potencia radica tanto en la propia coherencia del diseño como en los ajustes que en cada caso se le han realizado para adecuarlo a los nuevos lenguajes y circunstancias. El proyecto, que asentaba los sujetos (monarquía, clero «nacional», la aristocracia munida de valores cristianos); los conceptos (fórmula si rex eris, catálogo de virtutes principescas, etc.), las instancias (concilios, tribunales regios, monasterios/ cárcel) y finalmente los mecanismos para llevarlo a cabo (intervenciones «literarias», penas de excomunión, etc.), resultaba una de las fuerzas fundamentales que otorgaban realidad al regnum visigothorum -efecto complejo y siempre inestable de dispositivos eclesiásticos, monárquicos y aristocráticos, tributarios éstos de aquellos dos.

En segundo lugar, la variedad de alternativas, instrumentos y recursos que, de modo cada vez más generalizado, desarrollan las experiencias de retiro al eremos durante el siglo VII. Como demuestra la propia trayectoria de Fructuoso, en esta coyuntura la opción monacato/ vida eremítica no es irremontable y excluyente sino que se registran estados de fluidez entre ambas. La distinción verdaderamente importante en la coyuntura visigótica es la relación que cada sector mantiene con la respublica, es decir, el compromiso que está dispuesto asumir con la marcha de los asuntos «de todos». Heredero de los padres tebanos pero también de las tradiciones de Gregorio el Grande, gran parte del monacato occidental colabora con los poderes públicos. La diferencia que los separa del proyecto troncal diseñado por Isidoro para el reino es el rol de mediación indispensable que asignan a los monasterios. Otros sectores de ascetas radicalizados, poniendo mayor énfasis en los modelos tebanos, elaboran opciones corrosivas de los poderes instituidos. Apurémonos a afirmar que la existencia de estos proyectos no es causa directa de la caída del reino: otros elementos, como las disputas por el trono, la coyuntura militar, la actividad de otros sujetos contrarios también al régimen, hicieron asimismo su parte.

En tercer lugar, la evolución de la sociedad hacia una verticalización progresiva. Esto no es resultado de la debilidad de una monarquía que encarna los valores «públicos» asaltada por una aristocracia enrolada en la defensa irresponsable de los valores «privados»; sino que es motorizada por la propia dinámica de la institución regia e imitada por otros grupos con alguna capacidad de amalgama. 
